\title{
The Technological Disruption of Insurance Industry: A Review
}

\author{
Antonella Cappiello, PhD \\ Associate Professor \\ Department of Economics and Management \\ University of Pisa \\ Italy
}

\begin{abstract}
The paper focuses on the digital transformation that is greatly affecting the insurance industry and forcing radical change upon corporate culture, products and processes, customer relationship and relations with the sector's various competitors. By responding to three research questions, the paper aims to contribute to the academic discussion and proposes to offer useful cues of reflection to the insurance management, since the dissemination of new technologies needs to move towards continuously updated business models.
\end{abstract}

Keywords: insurance business models; Insurtech; insurance digital transformation; insurance disruption; insurance innovation; insurance value chain.

\section{Introduction}

As Schmidt (2018) points out, a broader "fourth industrial revolution" technology - such as cloud computing, telematics, the Internet of Things (IoT), mobile phones, blockchain technology, artificial intelligence/cognitive computing, and predictive modelling - is affecting the entire insurance business model, enabling new ways of communicating, information sharing, and insuring. In this regard, scholars and practitioners refer to InsurTech as a distinct branch of FinTech (Schueffel 2016)related to digital technology applied to the insurance sector (Nicoletti 2017; Chishti and Barberis 2016; Drummer et al. 2016; Mackenzie 2015; OECD, 2017). They consider InsurTech to be any technology-driven innovation in the insurance industry: software, applications, start-ups, products and services (Baumann, 2018; Chester et al., 2018, Swiss Re Institute, 2017). Though the insurance industry has been one of the slowest sectors in adapting to digital transformation, the now unrestrainable digitisation process is greatly affecting insurance companies and forcing radical change upon corporate culture, products and processes, customer relations and relations with the sector's various competitors (Albrecher et al., 2019; IAIS, 2017).In agreement with assertions by Eling and Lehmann (2018), we suggest three broad categories of change in the insurance industry: (1) new technologies change the way insurers and customers interact (e.g. social media, chat-bots and robo-advisors); (2) new technologies can be used to automate, standardise and improve the effectiveness and efficiency of business processes (e.g. online sales and digital claims settlements); (3) new technologies create opportunities to modify existing products (e.g. telemetric insurance) and develop new ones (e.g. cyberinsurance).

Several media articles and studies, mostly by practitioners and fewer from academic researchers, attempt to investigate the impact of digitisation applied to the insurance sector (Segev and Vickers 2017; Muller et al., 2015; Willis Towers Watson, 2017). They analyse the strategic implications of new technologies on cost structures (Freysoldt et al., 2018; Berger et al., 2016; Catlin et al., 2015), business processes (KPMG, 2019), customer satisfaction (Larsson, and Broström, 2019; Moneta, 2014), human resources (Johansson and Vogelgesang, 2015) and newly emerging risks (Singh et al., 2020; Egan, 2019; Biener et al., 2015).

Digitalisation is destined to deeply modify the financial and insurance ecosystem, impacting all activities that compose the whole insurance value chain, from product development to pricing/underwriting, sales and distribution, policy and claims management, and asset and risk management (Eling and Lehmann, 2018).Furthermore, insurance market players are now faced with a new insurance scenario 4.0 that will enable them to become part of a new ecosystem, generated by the development of connections between traditionally separated sectors and new competitors. Every player in the insurance sector is called upon to face and operate in a macroeconomic context in which InsurTech start-ups, i.e. young companies that pursue technology-driven business models, are expanding at a rapid pace. The focus of these new market entrants has shifted from mere software solutions to activities that clearly compete with those of insurance companies and brokers (Braun and Schreiber, 2017). 
The quicker the insurance business adapts to and integrates the new digital innovation, the more likely traditional insurers are to survive, since the market context is changing rapidly and is being driven by technology.In relation to the above scenario, the following research questions are proposed:

Question 1: Are InsurTech start-ups the great disrupters of traditional insurance intermediation?

Question 2: What impact does technology have on traditional insurance intermediation processes?

Question 3: How does the use of new technologies change customer relations? How does it influence customer loyalty?

\section{The spread of InsurTech start-ups}

In last two decades, one type of technological start-up, generically defined as "InsurTech" start-up, gaineda considerable market share in the insurance sector (Tanguy and Lorenz, 2017; Swiss Re Institute, 2017).Investments have increased exponentially, from 130 million dollars in 2011 to 2.7 billion in 2015. Further future growth of InsurTech platforms is envisaged, which would bring the fundraising from 175 billion dollars in 2016 to 235 billion dollars in 2021 (Kaesler, 2019). The placement of investments shows homogeneity on a global scale: 46\% of all investments are in the United States, 40\% in the EMEA area (Europe, Middle East, Africa) and 14\% in the Asia-Pacific area, with the prospect of progressive growth in the latter regions over the next few years (McKinsey, 2018).Most InsurTech investments are concentrated in innovation in the non-life compartment, particularly in the health and motor segments. However, diversification by area is growing and if investments were primarily concentrated in marketing and distribution, which are still predominant, they now extend to solutions in the field of analytics and underwriting on demand, namely the specific activity of selection and risk assessment of policies sold to policyholders. The trend is to intervene in all phases of the insurance value chain and even different insurance sectors than the non-life compartment.

Question 1: Are InsurTech start-ups the great disrupters of traditional insurance intermediation?

The main differences that distinguish the incumbent companies from the new start-ups are essentially attributable to aspects pertaining to the approach to the market, the kind of interaction between the policyholder and the insurance company and the features of the service provided (Volosovich, 2016). The marketing approach adopted by insurance companies can be defined as product-oriented, since they focus on offering a better product than their competitors. An indirect connection is established between the seller and the consumer; the service provision is mainly focused on product development and, at a later stage, on its distribution. On the other hand, the marketing objectives of start-ups are process-oriented. Emphasis is placed on offering the best experience while receiving the product. In this case, the relationship with the consumer is direct. The automation of processes allows for greater connectivity: distribution can also take place through chat-bots and robo-advisors in order to optimise time, place and customer needs. The service provision is mainly focused on promoting the dissemination of information about the product to the right people at the right time and in the right place. InsurTech companies are able to adopt decision-making processes driven by data analysis in order to promote innovative and customised products and services based on customer experience. All stages of the customer's journey and the value chain may be affected by the InsurTech phenomenon. In fact, the macro trend of digital innovation is leading to a much more fluid state in the sector, where each value proposition can become the integration of a set of multiple modules belonging to different players. At the same time, the boundaries are increasingly blurred between the classic roles of distributor, supplier (at times from another sector), insurer and reinsurer.The context seems to favour further growth of InsurTech, despite the high level of regulation characterising the insurance sector (Boyer and Nyce, 2011).

Conversely, the very presence of entry barriers hinders access to the market by global digital giants such as Google, Facebook and Amazon. Without players in a strongly dominant position, the sector has the possibility to develop gradually and widely, giving InsurTech the time and room to manoeuvre to gather funding and develop new solutions. InsurTech start-ups generally adopt very linear business models focused on specific areas and rich in technological content almost entirely dedicated to innovation in the insurance sector. Most use artificial intelligence, specifically machine learning, and possess great capacity for Big Data analysis and processing. Due to their significant digitisation, these start-ups are able to seize the opportunities offered by the market more swiftly than traditional companies. As such, they often have a culture that strives for and honours innovation and a mentality that places them in pole position in sector change (Catlin and Lorenz, 2017).In the early stages of their market entry, the innovative business model of InsurTech start-ups raised concerns about whether they would constitute a threat to the incumbent companies, due to the process named "digital disruption" (Naylor, 2016).However, the difficulties that a start-up might encounter are manifold, so some tech-led initiatives in insurance will inevitably fail. Factors of disadvantage are due to a poor knowledge of the market, the lack of an appropriate business model as well as the high level of competition in the insurance sector, characterized by many complexities and a high level of technical content. If the new players generally have strong skills in terms of customer experience, simplification and speed of processes, traditional companies have a significant advantage when compared to the competitors entering the sector, 
Namely the considerable reputation they enjoy on the market and huge pool of information about customers in terms of biographical data and, above all, risk profiling. In addition, the size of incumbent companies, with their conspicuous capital structures and the possibility to access new resources fairly easily, enables them to enter new market sectors, improve their services, support the launch of new products and attempt risky strategies. Moreover, recent surveys report that customers do not seem ready to abandon traditional insurance providers, as they consider them to be more reliable in terms of security and protection against fraud, attributing great value to brand reputation and personal interaction (Capgemini and Efma, 2019).

It follows that InsurTech and Big Tech do not pose an immediate competitive threat to established insurers. A drastic disintermediation of insurance companies, which would also imply profound innovation of the incumbent business models, does not seem to lie ahead in the short-to-medium term (Braun and Schreiber, 2017).Insurance companies are beginning to perceive new start-ups not as market disrupters, but rather as potential partners. To improve their products and customer service and limit the damage deriving from the arrival of new entrants, insurance companies have started signing partnership agreements with InsurTech stat-ups in order to build profitable partnerships with new operators and, on the other hand, to safeguard and possibly increase their market share. These initiatives bear witness to the fact that incumbent operators understand the potential of the InsurTech sector and to consider the digitisation of their business model as positive (Munich Re, 2016).An increasing number of insurers now regard investment in digitisation as a priority, especially considering that the sector has lagged behind its financial services peers in adopting digital technologies owing to regulations, reluctance and cost (Willis Towers Watson, 2017).

Many incumbent insurers are seeking to upgrade their digital capabilities, especially in order to boost customer engagement and collect data about new risk pools. Furthermore, the majority of entrants also seem willing to adopt a collaborative strategy with the incumbent companies. The development of alliances with new competitors (such as InsurTech suppliers) allows the incumbents to take advantage of the expertise, dynamics and ways of doing business, which, by its very nature, the insurance industry could not have developed. Big Data analytics and Blockchain projects are now the most interesting developing areas in the medium term for the insurance sector (Braun and Schreiber, 2017). There are several forms of collaboration established between traditional insurance companies and start-ups, which are sometimes present in the same business model:

1. investments in venture capital funds. At the moment, this is the main kind of partnership between incumbent companies and start-ups and it aims to gain InsurTech shares, in order to acquire control over this sector and take advantage of the technological innovation developed. Many companies have created ad hoc venture capital funds: for example, AXA has invested about 450 million dollars in software development, artificial intelligence and cybersecurity systems; MunichRe has earmarked 68 million dollars for the development of IoT tools for the InsurTech sector;

2. entering into a strategic partnership with InsurTech start-ups, aimed at outsourcing or improving some stages of the value chain. AXA collaborates with some e-commerce platforms, such as Alibaba to distribute products in Asia; Allianz collaborates with Simplesurance to offer products on online channels in Europe;

3. configuring accelerators and business incubators in order to create and develop new technologies, promote innovative ideas and business models. Some examples include Kamet, owned by AXA, AllianzX, MetLife's Lumen Lab and Manulife's Lab of Forward Thinking;

4. InsurTech acquisitions by incumbent insurance companies. Though these acquisitions now play a less relevant role, we can assume that investment strategies will move towards mergers and acquisitions in the short term, in order to pre-empt competitors and acquire better control over the technological innovation needed (Deloitte (2018).

Insurance companies use different selection parameters in order to select the InsurTech model in line with the strategic objectives set. Short- and medium-term evaluations are carried out by analysing the value added to the value chain, impact on consumers, the effect on business lines, ease of integration, opportunity costs deriving from the failure to collaborate and the modular nature of offers. Long-term evaluation, on the other hand, adds the analysis of market potential, the ability to generate profit over time, to meet regulations and to integrate into an ecosystem (Capgeminiand Efma, 2019).According to McKinsey (2019) research, the real difficulty is finding the right combination of collaboration between these two types of businesses. Future business models will be marked by close partnerships where incumbents will focus their activity on customer relations development, while InsurTech, as innovators and bearers of new technologies and applications, will act on the value chain, providing technological support to this process of change. The outcome of this collaboration is a reorganisation of the traditional insurance value chain, which will involve increased efficiency and flexibility, as well as the ability to respond quickly to market requirements (Deloitte, 2018). 


\section{Technology and insurance value chain}

The on-going digitisation process has immense impact on all activities that make up the insurance value chain, i.e. the basic tool introduced by Porter (1985) to examine all activities that a firm performs and how they interact to provide a competitive advantage or whether they have the potential to create a competitive advantage (Capon, 2008).

\section{Question 2: What impact does technology have on traditional insurance intermediation processes?}

Adapting the five primary activities of Porter's value chain - formulated for the general industry - to the insurance sector, we can identify the activities that form the insurance value chain and the technological solutions which allow for new ways of communicating, sharing information and insuring (Cappiello, 2018)(see Tab.1).

\begin{tabular}{|c|l|}
\hline $\begin{array}{c}\text { Product } \\
\text { development }\end{array}$ & $\begin{array}{l}\text { - The use of Big Data facilitates new behavioural, granular data collection and enables } \\
\text { service personalisation }\end{array}$ \\
& $\begin{array}{l}\text { - Telematics may reduce associated risks but create new ones, such as cyber risk } \\
\text { - Product/service innovation and diversification }\end{array}$ \\
\hline $\begin{array}{c}\text { Sales and } \\
\text { Distribution }\end{array}$ & $\begin{array}{l}\text { - Comparison platforms present customers with a comprehensive choice of all kinds of } \\
\text { insurance covers and in some cases allow to buy insurance online }\end{array}$ \\
& $\begin{array}{l}\text { - Offering innovation and diversification } \\
\text { - InsurTech start ups entry in the insurance market from adjacent markets }\end{array}$ \\
\hline Underwriting & $\begin{array}{l}\text { - Instantaneous information and Big Data allow more predictive and evaluative analytics } \\
\text { - Finer segmentationis driven by greater processing capabilities }\end{array}$ \\
\hline Claims & $\begin{array}{l}\text { - Telematics provides instantaneous information which can help insurers with more accurate } \\
\text { claims assessment and reduce fraud }\end{array}$ \\
& - Technology decreases processing time \\
\hline
\end{tabular}

Source: own processing

Product design and development mainly avails itself of Big Data analytics, which is combined with the use of IoT systems of interrelated sensors/devices - and Blockchain ledgers that allow for development of "smart contracts" that are capable of executing or enforcing by themselves, in the complete absence of human intervention. The collection and analysis of Big Data facilitate knowledge of potential customers and identification of their risk profile. They improve the competitiveness of the products and services offered by adapting offer personalisation to customers' needs in terms of quality and price. If technological progress has fostered access to the precious asset that is information, Big Datamanagement systems allow owners to achieve a far superior result, namely to process, correlate and analyse the data available and to draw new information and forecasts from this process in real time and with a high level of probability. The ability to collect and use Big Data proves to be crucial in order to analyse the vast quantity of information, structured and unstructured (Anchen and Dowe, 2019), collected by telemetric devices, social networks and other sources (customer feedback, etc.). Machine learning algorithms are developed in order to improve the quality of data analysis to be used for customer segmentation and risk allocation.

IoTcould revolutionise product design by opening up many new opportunities in connected home and connected health solutions. Among IoT systems, we find wearables devices, i.e. smart objects able to monitor policyholders' state of health in real time, thus allowing them to receive customised offers and respond promptly to sudden illnesses or check customers' habits. Cheap, connected monitoring devices offer a fundamentally different way of assessing and, crucially, mitigating risk, thus also reducing the rate of fraud by means of constant monitoring of risk positions (IHS Markit, 2016).In this scenario, telemetric may reduce associated risks, yet create new ones such as cyber risk, mobile phone radiation risk and the risk of contact with nanotechnology materials. In addition to product design, digitisation is helping in the underwriting and pricing of new and existing insurance products. The insurance market is characterised by information asymmetries. From the point of view of insurers, these mainly concern the need to find adequate information about the customer's risk profile. A decisive factor in the success of an insurance business model is the insurer's ability to estimate the cost of risks as accurately as possible. New technologies are able to reduce the problem of information asymmetries thanks to the refinement of risk level calculations, as adopted by companies on the basis of the interpretation of the insured party's data, which are collected using intelligent sensors and devices and allow for a more precise identification of the insured risks. In this regard, IoT/Big Data Analytics Technologies open the door to new ways of assessing and managing risk and claims. Risk selection is becoming ever more accurate and precise. The ways in which technology is improving or will improve risk selection include: i) the use of data gathered from connected sensors (IoT); ii) the use of Big Data to enrich underwriting decisions; iii) forward-looking, sophisticated risk measurement (catastrophe modelling); iv) digitalisation of insurance, which makes data more readily analysed and products more readily adapted (Morgan-Stanley/ BCG, 2014). 
Using analytical techniques, insurers can assess their customers' needs, target products and services to individuals and businesses, support underwriting decisions and reduce the cost of fraudulent insurance claims. In this regard, the importance of Big Data lies not just with the collection and storage of large and disparate pieces of information, but also in the ability to analyse and extract tangible and useful knowledge from said data. In addition, we believe that by combining more and different types of information, we can reduce problems related to the incompleteness of particular pieces of data (including the likelihood of errors, inconsistency of formats, inaccuracy of data processing, etc.)(Cukier and Mayer-Schenberger, 2013).At the same time, the widespread use of Big Data entails risks relating to the permissible and appropriate use and management of customers' data. Insurance companies must obviously show a deep sensitivity in all aspects related to privacy, with particular emphasis on the protection of data regarding their insureds from possible piracy attacks.

The new risk selection methods enable insurance companies to abandon the traditional pricing model - as well as the one for the calculation of claims reserves - which was based on statistical-actuarial methods of historical data analysis, and are beginning to use predictive models that detect the risk profile in real time thanks to the use of telematics. Smart analytics, predictive modelling and connected telematics devices assist insurers in designing products and setting premiums based on how insured parties actually behave, rather than using general proxies, as well as they make policy and claim management more efficient (OECD, 2017).

As new hazards are identified in real time, insurers can improve their data sets to better manage eligibility, underwriting and monitoring policies risks. Information is also analysed and processed by algorithms in order to accurately calculate the technical provisions to be held in the event of a claim. This enables insurance companies to use the resources available in a more efficient way, directing them towards investments with a greater rate of return. If the core business of insurance is risk selection and the price determination for taking them, the current evolution towards a full use of Big Data will radically alter the data type itself, the way data will be analysed, claim management and relationships with customers. The growing proliferation of new data about insured parties collected via sensors and smart devices allows for a more granular underwriting and monitoring of individual risks. Smart analytics is the term used to describe the systematic use of data. To this end, both structured data from a range of sources (such as sensors, written documents and data published on the Internet), and unstructured data gleaned from conversations or letters, is gathered. Software solutions recognise patterns in the data and cluster them, giving insurance companies more detailed insight into the behaviour and needs of their customers. Thanks to the use of telematics and wearable technologies, it is possible to gather some parameters in real time during the entire policy life cycle, such as driving behaviours and health metrics of insured parties. The combination of rich customer data, telematics and enhanced computing power makes it possible to adopt premiums based on the actual use and conduct of the insured. Insurers can use the real-time data captured through telematics devices and powerful analytics to re-assess the current risks and re-calculate the premium for current risks at regular intervals. Insurers can develop tailor-made products with pricing adjusted to individual risk levels and a very accurate selection (Porter and Heppelman, 2014).

Companies with innovative pricing models and information about individual risks can better identify the lowest-risk clients, while self-informed, higher-risk clients may seek out less sophisticated providers offering more attractive rates based on less information. In this environment, late adopters of new technology would be more susceptible to the threat of adverse selection. The opportunity to collect and analyse in real time a wide variety of data is transforming claims processes, enabling insurers to improve fraud detection, cut loss-adjustment costs, and eliminate many human interactions. Artificial Intelligence and Big Data are the principal instruments to adopt in order to carry out claims management correctly: thanks to the sophisticated analysis, it is possible to prevent false accident fraud, automate claims calculation and manage their payment. By lowering the accident rate, the relationship between the policyholder and the insurer changes: not only is there interaction in the event of an accident, but they become partners in loss prevention. In this regard, innovation applied to claims management has a dual positive effect: it reduces the cost of indemnities (both administrative costs and the total amount of indemnities, reduced thanks to fraud prevention) and it increases customer satisfaction thanks to faster payment procedures, and claims management taken anytime and anywhere.

\section{The digitisation of insurance distribution}

Sales and distribution are undoubtedly the value chain components that have been affected most by the technological evolution. The application of digital technologies has vastly changed the service delivery process, the way they are used and, consequently, the customer relationship. In order to upgrade communication methods and improve sales activities, insurance companies focus on the design of mobile apps, websites and official pages on the main social networks. They are also attempting to implement distribution methods and customer relation management through chat-bots and robo-advisors, which are highly technological systems. 
By reducing interaction time thanks to the digitisation of distribution channels, insurance companies can improve their efficiency by cost reduction and better pricing policies. Furthermore, they can consolidate/expand their market share thanks to a careful management of customer relations. In this respect, it is necessary to highlight that the distribution of the insurance services implies a close interaction between insurer and customer, which becomes an integral part of the delivery process itself.

It is true that during the stages of acquisition and use of the insurance service, more or less frequent contact is needed between the customer and the insurer(Normann, 2001;Dumm and Hoyt, 2003). The company can indeed act to modify how the service is enjoyed at any time (for example, by varying the premium or certain conditions). On the other hand, the user's conduct may influence the delivery and therefore use of the service (for example, in the case of increases in risk or moral hazard behaviour).Therefore, an interactive process is created between the two counterparties that together contribute to the creation and maintenance of the insurance relationship. The interdependence between production, distribution and consumption phases makes the delivery system decisive in the connotation of the service, as well as in its qualification with the customer.

\section{Question 3: How does the use of new technologies change customer relationship?}

Product differentiation can be implemented through a technological, relational or organisational change that affects the constituent elements of the delivery system, and consequently modifies the client's use of the product (Nightingale, 2003; Pires et al., 2008).It is evident that the technological evolution becomes critical when renewing the production and distribution processes of insurance services, as well as their innovation (Coelho et al., 2003).In fact, in addition to making a significant contribution to the rationalisation of the delivery systems of insurance services, the use of digitised channels also promotes the possibilities of their differentiation and innovation (Coelho and Easingwood, 2005). Therefore, by overcoming the direct relationship with sales staff and implying a greater involvement of the customer in the process of delivering, technological solutions significantly affect the degree of novelty of the service itself (Badoc, 1986; Eiglier and Langeard, 1987; Kabadayi et al., 2017).The growing dissemination of information technology allows for the expansion of distribution channels, including technological ones, while promoting the transformation of the agency in relation to both its physical and functional configuration, and its role within the relationship with the market. In this respect, Heinhuis and de Vries (2009)point out that the expansion of operational boundaries, financial innovation and the changing needs of the market have led to the emergence of favourable conditions for diversification, as well as for a certain specialisation of the delivery systems. As is obvious, this trend leads to a careful assessment of the inherent problems in the composition and coordination of the entire distribution system related to the products offered. The different nature of the needs expressed in the various market segments, and the consequent specificity of the products, therefore, require special methods of delivery, which relate to certain distribution channels (Coelho and Easingwood, 2008).

The choices for the design of differentiated delivery systems are therefore closely linked to the analysis of the traits and competitive dynamics of the strategic business areas in which the company operates. These business areas are defined by the following key elements: i) customer segments; ii) the needs they express (types of services), and iii) the ways to satisfy said needs (production-distribution technology).In this regard, it is worth mentioning that insurance products are placed between the extremes of simplicity and low unit added value on the one hand, and of high complexity and significant added value on the other; thus, elementary services and complex services are identified.The first category includes all services characterised by simple operations that have a minimum content of personalisation and are easily standardised (e.g. motor insurance, home insurance, etc.).For the distribution of such services whose demand is determined, in particular, by price and comfort - the latter referring to the proximity of the delivery point and transaction execution speed - the insurance company develops relatively inexpensive delivery systems based on the use of advanced technologies. The complex, or specialist, services, on the other hand, have opposite characteristics: in a nutshell, they require a high degree of personalisation and are of high added value (for example life insurance and pension products). In this case,customers are sensitive to the quality of the service offered and to the personal relationship, since these services require some assistance and consultancy services before and after the sale.It follows that it is not possible to transfer a large part of the executive operations to automatic devices, as it detects the degree of relationship "personalisation"; the company must have delivery systems that allow for the development of unstructured, high-content "service" relationships. For the distribution of complex services, for which a high level of interaction with the customer is required, companies therefore provide high-quality channels with a strong personalisation and operational flexibility. In this respect, a delivery system implying a good level of contact with the customer is conceivable; this can be done at the agency, or through dedicated delivery networks (Cappiello, 2018). The complexity of the delivery system tends to increase alongside the complexity of both the service provided and the relationship with customers. 
In general, we can argue that the most complex delivery systems, characterised by the highest added value, are dedicated to the distribution of product services with higher specialist content, such as life insurance policies with fairly high investments. For these services, technology is applied to improve the efficiency and effectiveness of the intermediaries. The delivery systems characterised by a lower level of complexity and a low added value are dedicated to elementary services, such as non-life insurance policies. The use of technology, allowing for standardisation and widespread distribution systems, makes it possible to achieve advantages in terms of cost structure - consequently developing competitive strategies based on price - and to effectively meet customer expectations, in order to increase the distribution of sales points, reduce waiting times and expand service hours (Thornton and White, 2001).

The increasing diversification of the services offered requires a greater specificity of the delivery systems. Specialisation of the latter can be carried out within the same distribution channel (in particular at the agency), or give rise to relatively dedicated channels. As is evident, it is impossible to create a univocal solution valid for every type of company, since the choices for the best combination of the different distribution channels and their organisation derive from the assessment of their efficacy and efficiency, and therefore of the potential synergies, or diseconomies, relating to them, not in a theoretical line, but in relation to the specific company. This is conditioned by several factors, including but not limited to the size of the company, the geographic extent of the markets served and the competitive dynamics related to them, alongside, of course, the type of products/services offered and the characteristics of the demand segments. Moreover, the selection of the various types of distribution channels is strongly influenced by the product policies placed by the company and the characteristics of the segments served, as well as by inheritance factors. The latter pertains particularly to the existing delivery structure, which clearly constrains and conditions the strategic choices relating to the rationalisation and restructuring of the entire delivery system, including the enlargement of the range of distribution channels. The adoption of a delivery system which provides for the use of a wider range of distribution channels, endowed with greater specialisation, can allow, in addition to the recovery of efficiency, for the achievement of a more competitive effectiveness, since the greater specificity of the channel is suited to satisfying the needs of the target market more appropriately and therefore to optimising the customer relationship.

Technological advancements allow for the activation of new delivery systems, and therefore new distribution channels, in the face of specific combinations of services offered/customer segments served. These distribution channels are a real innovation in the delivery systems that, in the past, were closely linked to physical support(Stepanek and Roman, 2017).As is clear, the automation and outsourcing of some production-distribution processes and easily standardised services thanks to the use of digitalised procedures, lead to an improvement in the operational efficiency and effectiveness of the whole company delivery system. Besides encouraging the structural rationalisation of the distribution network and the reduction of its costs, the use of technological channels also allows for the improvement of service quality, such as performance speed and precision, and offers the possibility to satisfy customer needs as closely as possible to where they are expressed. Digitisation may unlock new competitive and marketing opportunities, since it allows for remote interaction with the user. However, the increasing automation, if not used interactively, contributes to a progressive depersonalisation of the insurer-customer relationship. This becomes more relevant in relation to the intangible nature of the insurance service, which is only easily assessed in its qualitative aspects at the time of use. The constituent elements of the service delivery system therefore have a significant impact on the quality, as perceived by the customer; this can be understood as the result of the combination of different elements such as ease of access and convenience of enjoyment, time frames and reduction of material errors, the transparency and cost-effectiveness of the relationship, the professionalism and courtesy of the intermediating employee who simultaneously manufactures and sells the service (Donnelly et al., 1985;Normann, 2001; Kotler, 2001).Technological innovation clearly offers the opportunity to improve many of these aspects; it is also able, especially for less complex products, to increase the frequency of consumer interaction, thus offering the possibility to increase customer loyalty(Accenture, 2017).However, the fragmentation of contact points due to the expansion of direct digital channels, as well as the customer's economic and cultural evolution, contribute to increasing the mobility of the latter by making it more difficult to establish a lasting relationship. Moreover, the depersonalisation of the relationship can tend to reduce customer loyalty, since quality judgements are increasingly expressed on the basis of technical and economic considerations, and less and less on the basis of emotional factors (Reicheld, 1996; Schwarz et al., 2014). The loss of direct contact with the customer is undoubtedly a negative factor that must not be neglected. It is therefore necessary to balance the need for a personalised relationship with customers with the benefits offered by automation; this objective can be achieved by seeking a marked standardisation of elementary services, which needs to be associated with a greater specialisation of the company-client relationship. In this regard, it is appropriate to adopt a personalised approach to the market according to the logic of customised marketing. 
Through a more precise identification of different needs and different requirements, greater personalisation can be obtained in the delivery of services and in communication with the reference market. While, on the one hand, the tendency to use automated channels is growing for basic services, on the other, especially for more complex services, the demand for a greater personalisation of the relationship and communication with the company is increasing(Hanninen and Karjaluoto, 2017).It is therefore necessary to strive for continuous improvement in the approach to communication with the reference market in order to possibly renew and innovate the relationship with customers in view of a complete fulfilment of their expectations.

\section{Conclusions}

With regard to the existing literature, this paper has shed light on the impact of the on-going digitisation on insurance intermediation processes. The process involves the whole insurance ecosystem, facilitating the entry, competition and collaboration of new players. To the first question - are InsurTech start-ups the great disrupters of traditional insurance intermediation? - we have responded in the negative, arguing that the empirical evidence and academic studies tend towards relationships of synergy rather than competition between the two parties. As it stands, InsurTech start-ups do not seem to pose an immediate competitive threat to incumbent insurers. Several insurance companies are therefore looking for new business and partnership models with InsurTech start-ups in order to innovate every phase of the value chain. However, the findings pave the way for further research questions: are there genuine disrupters that may fundamentally change the traditional insurance sector? What role is Big Tech such as the likes of Google, Facebook or Amazon destined to have in the insurance ecosystem?

The second question - what impact does technology have on traditional insurance intermediation processes? - is answered by analysing the insurance value chain in light of the framework of Porter's Value Chain. Requirements for new digital solutions are challenging legacy systems, and new technologies are offering new options for system organisation. It has been shown how digitalisation has a profound impact on all phases of the value chain of the processes and offers benefits by reducing asymmetric information, properly combining the right pricing, responsive risk management, appropriate underwriting and accurate claims, and fast and reliable delivery systems. On the other hand, there are limitations to the entry of newer competitors into the insurance market from adjacent markets. Moreover, there is increasing exposure to operational risks, including new generation risks. In this regard, the use of new technologies raises many research questions. These include: will the consumer's increasing knowledge mean that some providers might seek to offer services only to the most profitable, or least risky segments and shut others out of the market? Can the fundamentals of insurance mechanism still function in light of the increasingly pronounced risk prevention and mitigation? This brings us to the third question: How does the use of new technologies change customer relationship? An initial approximation might lead us to state that technological innovation presents new opportunities to satisfy customer expectations, as many studies on the subject confirm(Larsson and Broström,2019).Customer satisfaction is certainly increased by the possibility to manage the use of insurance cover and any claims independently, anywhere and at any time(Akroush and Mahadin, 2019;RochinDemong et al., 2019; Kaewsawad and Li, 2018).Customers who desire more and more new ways of purchasing insurance and managing risk - including more fitfor-purpose cover and services and more immediate delivery - and who wish to interact through various channels when searching for and purchasing insurance products greatly influence this evolution, which changes the traditional "faceto-face" business model. We must nevertheless consider that the spread of information (i.e. comparison sites) can diminish the loyalty of the insured. This may be exacerbated if increasing automation brings about a progressive depersonalisation of the insurer-insured relationship. Therefore, the increasing lack of human relationship due to the dissemination of digital distribution must move towards new digital-ready models of insurance intermediation, which require customer centricity and continuous market research. More open-ended questions remain. Would greater personalisation of services and communication with the market, which involves developing an integrated communication strategy, make it possible to better reach the customer in order to: i) better understand customer preferences?; ii) create customers' new needs and anticipate them?; iii) increase loyalty?; and iv) monitor and oversee reputational dynamics that could otherwise elude control? We leave these questions for future research on digital technologies in insurance intermediaries to answer.

\section{Acknowledgement}

Funding: This study has not received funding.

Conflict of Interest: The author declares that she has no conflict of interest. 


\section{References}

Accenture, 2017.The future of insurance distribution.New models for a digital customer.

https://www.accenture.com/_acnmedia/pdf-38/accenture-reimagine-insurance-pov-final.pdf.

Akroush, M. and Mahadin, B., 2019.An intervariable approach to customer satisfaction and loyalty in the internet service market", Internet Research, 29 (4), 772-798.

AlbrecherH.,Filipović D., Koch-Medina P., Schmeiser H. e Loisel S., 2019. Insurance: models, digitalization and data science. Swiss Finance Institute. Research Paper Series, 19-26, June.

Anchen J. and Dowe A., 2019. Advanced analytics unlocking new frontiers in P\&C insurance, Sigma.4, 2-30.

Badoc M., 1986. Marketing pour le banqueetl'assuranceeuropeennes. Paris FR: Les editions d'organisation.

Baumann, N., 2018.A catalyst for change - How fintech has sparked a revolution in insurance. Available at https://www2.deloitte.com/content/dam/Deloitte/global/Documents/Financial-Services/gx-fsi-cataylst-forchange.

Biener, C., Eling, M. and Wirfs, J. H., 2015. Insurability of cyber risk: An empirical analysis. The Geneva Papers on Risk and Insurance--Issues and Practice. 40(1), 131-158.

Boyer M. and Nyce C. M., 2011. Market Growth and Barriers to Entry: Evidence from the Title Insurance Industry. Insurance and Risk Management.78(3-4), 283-315.

Braun A. and Schreiber F., 2017. The current InsurTech Landscape: Business Models and Disruptive Potential, Institute of Insurance Economics, University of St. Gallen. St. Gallen.

Capgemini and Efma, 2019. World Insurance Report 2019. https://www.efma.com/study/detail/30818.

Capon C., 2008. Understanding strategic management. London UK: Prentice Hall.

Cappiello A., 2018. Technology and the Insurance Industry. Re-configuring the Competitive Landscape. Cham: $\mathrm{CH}$, Springer.

Catlin T. and Lorenz, 2017. Insurtech - the threat that inspires. March, https://www.mckinsey. J. T. com/industries/financial-services/our-insights/insurtech-the-threat-that-inspires

Catlin T., Hartmann R., Segev I., and Tentis R., 2015. The Making of a Digital Insurer: The Path to Enhanced Profitability, Lower Costs and Stronger Customer Loyalty, McKinsey \& Company http://www.mckinsey.com/industries/financial-services/our-insights.

Chester A., Hoffman N., Johansson S. and BraadOlesen P., 2018. Digital Insurance in 2018 - Commercial lines InsurTech: A pathway to digital, https://www.mckinsey.com/industries/financial-services/our-insights/html

Chishti, S., and Barberis, J., 2016. The FinTech Book: The Financial Technology Handbook for Investors, Entrepreneurs and Visionaries. Chichester, UK: John Wiley \& Sons Ltd.

Coelho F., Easingwood C. and Coelho A., 2003.Exploratory evidence of channel performance in single vs multiple channel strategies.International Journal of Retail \& Distribution Management.31 (11), 561-573.

Coelho F. and Easingwood C., 2005. Determinants of multiple channel choice in financial services: an environmental uncertainty model. Journal of Services Marketing.19 (4), 199-211.

Coelho F. and Easingwood C., 2008.An exploratory study into the drivers of channel change.European Journal of Marketing.42 (9/10), 1005-1022.

Cukier K., and Mayer-Schenberger V., 2013. The Rise of Big Data: How It's Changing the Way We Think About the World, Foreign Affairs, 92 (3), 28-40.

Deloitte, 2018. A catalyst for change: How Fintech has sparked a revolution in insurance. https://www2.deloitte.com/content/dam/Deloitte/global/Documents/Financial-Services.pdf.

Donnelly J., Berry L.L. and Thompson T.W., 1985. Marketing Financial services: a strategic vision. New York: Dow Jones Irwin.

Drummer, D., Jerenz, A., Siebelt, P., and Thaten, M., 2016.FinTech: Challenges and Opportunities -How digitization is transforming the financial sector. McKinsey, Dusseldorf.

Dumm R. E. and Hoyt R. E., 2003. Insurance Distribution Channels: Markets in Transition, Journal of Insurance Regulation. 22 (1), 27-47.

Egan, R., Cartagena, S., Mohamed, R., Gosrani, V., Grewal, J., Acharyya M., et al., 2019. Cyber operational risk scenarios for insurance companies.British Actuarial Journal.24, 2019.

EiglierP.andLangeard E., 1987. Servuction, le Marketing des Services. Paris FR: McGraw Hill.

Eling M. and Lehmann M., 2018.The impact of digitalization on the Insurance Value Chain and the Insurability of Risks".The Geneva Papers. 43, 359-396.

Freysoldt T., Johansson S., Korwin-Szymanowska C., Münstermann B. and Vogelgesang U., 2018. Evolving insurance cost structures. How incumbents can adapt and save to remain competitive in the digital age. Insurance Practice, McKinsey\&Company. 
Hanninen N., and Karjaluoto H., 2017. The effect of marketing Communication on Business Relationship loyalty, Marketing Intelligence and Planning.35 (4), 458-472.

Heinhuis D. and de Vries E. J., 2009. Modelling Customer Behaviour in Multi-channel Service Distribution, Enterprise Applications and Services in the Finance Industry. 35, 47-63.

IAIS - International Association of Insurance Supervisors, 2017.FinTech Developments in the Insurance Industry. Basel, $\mathrm{CH}$.

IHS Markit, 2016. Usage-Based Insurance Expected to Grow to 142 Million Subscribers Globally by 20232. May. http://press.ihs.com/press-release/automotive/usage-based-insurance-expected-grow-142-million-subscribersglobally-2023-i).

Johansson S. and Vogelgesang, U., 2015. Insurance on the Threshhold of Digitization: Implications for the life and P\&C Workforce, McKinsey \& Company.

Kabadayi S., KomarovaLoureiro Y. and Carnevale M., 2017. Customer Value Creation in Multichannel Systems.The Interactive Effect of Integration Quality and Multichannel Complexity.Journal of Creating Value.3 (1), 1-18.

Kaesler S., 2019. A new industry model for InsurTech, May, https://www.mckinsey.com/industries/financialservices/our-insights/insurance-blog/a-new-industry-model-for-insurtech.

Kaewsawad S. and Li Z., 2018. The effects of service quality of customer service on total customers' satisfaction in case of buying life insurance via online channel, in Böhm S., Sid Suntrayuth S. (eds), 2018. Proceedings of the IWEMB 2018 second international workshop on entrepreneurship in electronic and mobile business, Publiqation, Germany.

Kotler, P., 2001.A Framework for Marketing Management. New Jersey: Prentice Hall.

Kpmg, 2019.Insurtech 10: Trend for 2019, March. https://assets.kpmg/content/dam/kpmg/xx/pdf/2019/03/insurtechtrends-2019.pdf

Larsson, A. and Broström, E., 2019. Ensuring customer retention: insurers' perception of customer loyalty. Marketing Intelligence \& Planning, Vol. ahead-of-print No. ahead-of-print.

Liedtke, P., 2007. What's insurance to a modern economy?, The Geneva Papers on Risk and Insurance-Issues and Practice, 32 (2), 211-221.

Mackenzie, A., 2015. The Fintech Revolution. London Business School Review, 26(3), 50-53.

McKinsey, 2018. Digital Insurance in 2018: driving real impact with digital and analytics, https://www.mckinsey.com/ /media/McKinsey/Industries/Financial\%20Services

McKinsey, 2019, https://www.mckinsey.com/industries/financial-services/our-insights/insurance-blog/a-new-industrymodel-for-insurtech.

Meier A. and Stormer H., 2009. eBusiness and eCommerce. Managing the digital value chain. Cham CH: Springer.

Moneta, A., 2014. The Customer-Centric Insurer in the Digital Era, Accenture, https://www.accenture.com/ D9/Accenture-The-Customer-Centric-Insurer-In-The-Digital-Era.

Morgan-Stanley/ BCG, 2014. Insurance and Technology: Evolution and revolution in a digital

Muller F., Naujoks H., Singh H., Schwarz G., Schwedel A. and Thomson K., 2015. Global Digital Insurance Benchmarking Report 2015, Bain \& Company.

Munich RE, 2016. Reinventing insurance for the digital generation. January. https://www.munichre.com/topicsonline/en/html.

Naylor, M., 2016. A Perfect Storm in Insurance: How to Survive the Looming Waves of Disruptive Technology. SSRN Electronic Journal, January.

Nicoletti B., 2017. The Future of FinTech.Cham:CH, Springer.

Nightingale P., 2003. Innovation in Financial Services Infrastructure, in Shavinina L.V. (ed.), The International Handbook on Innovation. Oxford UK: Elsevier Science Ltd. 529-547.

Normann R., 2001. Service Management: Strategy and Leadership in Service Business. New York: Wiley \& Sons.

OECD - Organisation for Economic Co-operation and Development, 2017. Technology and Innovation in the insurance sector.

OECD, 2019.Global insurance market trends

Pires C.P., Sarkar S., and Carvalho L., 2008. Innovation in services - how different from manufacturing?.The Service Industries Journal.28,1339-1356.

Porter M. E. and Heppelman J. E., 2014. How smart, connected products are transforming competition. Harvard Business Review.92, 11-64.

Porter M. E., 1985. The Competitive Advantage: Creating and Sustaining Superior Performance. New York: The Free Press.

PwC - Pricewaterhouse Cooper, 2014. Insurance 2020: The digital prize - taking customer connection to a new level. Rayport J. and Sviokla J., 1995. Exploiting the Virtual Value Chain, Harvard Business Review. Nov. Dec. 45-54. 
Reicheld F.F., 1996. The loyalty effect. Boston: Harvard Business School Press.

RochinDemong N.A. et al. 2019. Service quality factors and customer satisfaction on life insurance services. Journal of Islamic Management Studies, 2 (1), 22-31.

Scheuffel, P., 2016. Taming the beast: a scientific definition of fintech. Journal of Innovation Management. 4 (4), $32-$ 54.

Schwarz G., Naujoks H., Goossens C., Whelan D., Schwedel A. and Singh H., 2014. Customer Loyalty and the Digital Transformation in P\&C and Life Insurance. https://www.bain.com/insights/customer-loyalty-and-the-digicaltransformation-in-p-and-c-and-life-insurance/.

Segev I. and Vickers A., 2017. What the new world of insurance could look like, McKinsey \& Company. August.

Singh A., Akhilesh K.B., 2020. The Insurance Industry-Cyber Security in the Hyper-Connected Age. In: Akhilesh K., Möller D. (eds). Smart Technologies. Springer.

Stepanek L. and Roman P., 2017. Urban Insurance Industry Ideas Of Second Millenium, Ecoforum, 6, 1(10)

Swiss Re Institute, 2017. Technology and Insurance: themes and challenges, June.

Tanguy C. and Lorenz J. T., 2017. InsurTech — the threat that inspires. https://www.mckinsey.com/industries/financialservices/our-insights.

Thornton J. and White L., 2001. Customer orientations and usage of financial distribution channels, Journal of Services Marketing, 15 (3), 168-185.

vanRossum A., 2002. The Debate on the Insurance Value Chain.The Geneva Papers on Risk and Insurance, 27/1, 89101.

Venture Scanner, 2016. Insurance Technology Market Overview. https://www.venturescanner.com/blog/2016/insurance-technology-market-overview-q4-2016

Volosovich S., 2016. InsurTech: challenges and development perspectives. International Journal of innovative Technologies in Economy. 3/5, 39-42, November.

Willis Towers Watson, 2017. New Horizon: How Diverse Growth Strategies can Advance Digitisation in the Insurance Industry. January, 